\title{
The Long-Term Results of Localised Anterior Cervical Decompression and Fusion in Spondylotic Myelopathy
}

\author{
G. B. Irvine, F.R.C.S., W. E. Strachan, F.R.C.S. \\ Department of Neurosurgery, Freedom Fields Hospital, Plymouth, Devon
}

\begin{abstract}
Summary
A retrospective analysis is presented of 46 patients with cervical spondylotic myelopathy treated by anterior cervical decompression and fusion. In each case the spondylosis was localised and a maximum of two intervertebral levels was fused. Operation had been carried out 7.0 to 14.4 years (mean 10.0 years) previously and the mean age at surgery was 60 years. Disability was such that no patient was able to work prior to operation and only 10 patients $\left(22^{\circ}{ }_{0}\right)$ could walk unaided. The functional results, in terms of walking ability, show that 36 patients ( $78_{\circ}^{\circ}$ ) have been improved, six $\left(13^{\circ}{ }_{0}\right)$ remain unchanged and in 4 patients $\left(9^{\circ}{ }_{0}\right)$ the disease has progressed. Twenty nine patients $\left(63^{\circ}{ }_{0}\right)$ were able to walk without aid at the time of review. On a subjective basis 30 patients $\left(65^{\circ}{ }_{0}\right)$ felt that they had benefitted from surgery.
\end{abstract}

Key words: Spinal osteophytosis; Spinal cord compression; Spinal fusion.

\section{Introduction}

Myelopathy has been recognised as the most serious consequence of cervical intervertebral disc degeneration (Lunsford et al., 1980) and is considered to be the commonest cervical cord disorder during and after middle age (Crandall and Gregorius, 1977). In spite of this there is little agreement as to the most appropriate form of management. A great variety of methods of operative treatment have yielded a wide range of results. Posterior decompression with or without foraminotomy and dural grafting was the usual choice before the anterior approach was pioneered by Cloward (1958). Although the good results of anterior surgery for root symptoms is generally accepted, its effect on spondylotic myelopathy is still debated. The purpose of this study is to present 
the late results of anterior cervical decompression and fusion in 46 patients with myelopathy secondary to localised cervical spondylosis.

\section{Patients and methods}

Seventy nine patients with myelopathy secondary to localised cervical spondylosis were treated by anterior cervical decompression and fusion during the period 1968-1975. There was one post operative death - a 75-year-old emphysematous man who died 3 weeks following surgery from bronchopneumonia; six patients died subsequently from unrelated disease and a further 19 patients could not be traced at the time of review. Of the 53 remaining a total of 46 patients agreed to participate in the study. Their age (at surgery) and sex distribution is shown in Table I. No patient was able to work at the time of admission for surgery. Conservative measures had been employed extensively prior to referral and symptoms had been present for more than 1 year in $75 \%$ of the patients. Clinical examinaton revealed an approximately equal division between the five predominant spinal cord syndromes (Crandall and Batzdorf, 1966). A simple functional score of walking ability (Table II) was used to judge the severity of disease. There were no patients in Grade 1, $10(22 \%)$ in Grade 2, $23(50 \%)$ in Grade 3 and $13(28 \%)$ in Grade 4 . Myelography was carried out in all cases, there being a complete block in seven cases and a partial obstruction to the flow of contrast in a further eleven.

\begin{tabular}{lccccc} 
Table I & \multicolumn{4}{c}{ Age and Sex Distribution. 46 Patients. (Age Range 41-76 Years, Mean 60 Years). } \\
\hline Age & Under 50 Years & $50-59$ Years & $60-69$ Years & Over 70 Years & Total \\
\hline Male & 5 & 15 & 13 & 2 & 35 \\
Female & 1 & 1 & 7 & 2 & 11 \\
Total & 6 & 16 & 20 & 4 & 46 \\
\hline
\end{tabular}

Table II Four Grades of Walking Ability.

\begin{tabular}{ll}
\hline Grade 1 & No limitation \\
Grade 2 & Minor restriction. No walking aids required \\
Grade 3 & Greater restriction. Walking aids necessary \\
Grade 4 & Housebound \\
\hline
\end{tabular}

The surgical technique employed was that advocated by Cloward (1958) in which access to the cervical spine is gained through a $5 \mathrm{~cm}$ skin crease incision at the level of the cricoid cartilage with retraction of the trachea and oesophagus medially and the carotid sheath laterally. Using $20 \mathrm{lbs}$ halter traction and the Harris (1963) instrument modifications, decompression is achieved by drilling out the affected interspace (confirmed radiologically) and portions of the adjacent vertebral bodies. The posterior longitudinal ligament is not excised, but all degenerate disc material and any osteophytic projection is curetted out. Fusion is achieved with a pre-cut cylindrical bone dowel taken from the uppermost portion of the patient's iliac crest. No patient was refused surgery on the grounds of excessive severity or age. Nineteen patients underwent surgery at a single 
Table III Frequency of Operation at each Intervertebral Level. 73 fusions.

\begin{tabular}{lcccccc}
\hline Level & $\mathrm{C}^{3 / 4}$ & $\mathrm{C}^{4 / 5}$ & $\mathrm{C}^{5 / 6}$ & $\mathrm{C}^{6 / 7}$ & $\mathrm{C}^{7 / 1}$ & Total \\
Fusions & 14 & 15 & 30 & 12 & 2 & 73 \\
\hline
\end{tabular}

Table IV Functional Grade Pre-operatively and at Review. 46 Patients.

1

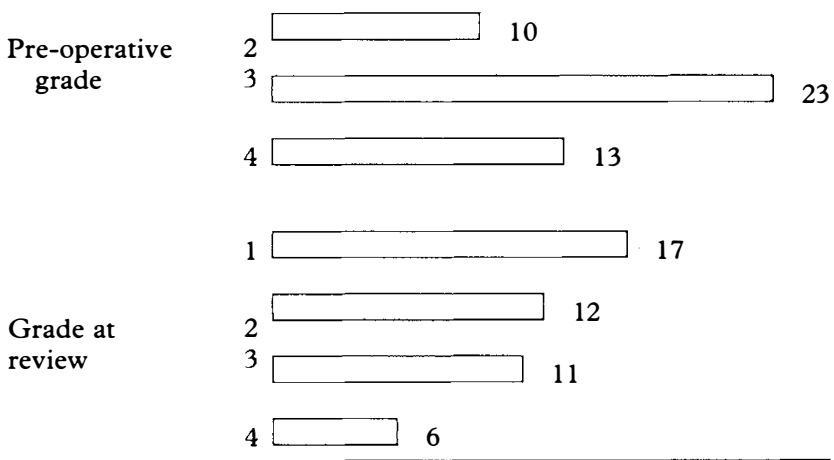

intervertebral level and 27 had two contiguous levels fused (Table III). Mobilisation was commenced at 24 to 48 hours, a painful donor site haematoma developed in a few cases but this was the only complication noted. Most patients were discharged from hospital in the second post operative week and subsequently all bone grafts incorporated uneventfully.

Follow up was by self-assessment questionnaire in all 46 cases. Patients were asked to give detailed information on their walking ability and any restrictions to the activities of daily living. They were questioned further on their general health and on their impression of the benefit or otherwise of surgery. In addition 12 patients agreed to attend for examination.

\section{Results}

The mean follow up period was 10 years (range 7 to 14.4 years). The questionnaire data was used to further grade each patient (Table IV). Seventeen patients indicated that they were unlimited in their walking ability. A further 23 reported some restriction and eleven of these patients required a stick for walking. Six patients were unable to get about outside their homes. Seven of the patients whose walking ability was limited reported that their general health and mobility were compromised by other unrelated pathology. The functional grade had improved in 36 patients $(78 \%)$, remained static in six patients $(13 \%)$ and worsened in four patients $(9 \%)$. Age at surgery, symptom duration, severity of disease or number of operated levels could not be shown to have a statistically significant relationship to outcome. Subjectively 30 patients $(65 \%)$ felt that operation had been beneficial.

The examined group were used primarily to verify the questionnaire responses and there appeared to be a good correlation. In these 12 patients, pain, spasticity 
and limb weakness appeared to be the parameters most improved. In one patient sensory deficit appeared for the first time several years after operation.

\section{Discussion}

The history of cervical spondylosis, together with its clinical manifestations, was detailed by Wilkinson in 1967; attention having been earlier drawn by Brain et al. (1952) to myelopathy and spinal cord compression. Since that time there have been many published reports of the effects of different therapeutic regimens on cervical spondylotic myelopathy with varying conclusions. The early surgical results (Northfield, 1955; Campbell and Phillips, 1960) appeared not to differ from the natural history of the untreated disease and this led to the suggestion that a very conservative approach should be the rule (Lees and Turner, 1963). The differences in results may be explained in part by selection of patients for inclusion and by the lack of absolute criteria for both disability and post operative improvement which render inter-series comparison difficult.

The patients in our group have an age and sex distribution similar to other studies and are unselected except that surgery was not offered to mildly affected cases. No patient was able to work pre-operatively and only 10 patients $(22 \%)$ could walk unaided; severe disability has been noted in a previous surgical series (Symon and Lavender, 1967).

The Cloward procedure is of proven value for the relief of radicular symptoms (Cloward, 1962) but early reports of its use failed to separate the results according to the clinical manifestations of cervical disc disease. Subsequently, it was shown that the results depended upon whether the symptoms reflected radicular or myelopathic involvement: those with myelopathy faring less well (Dohn, 1966). Following this observation, several reports of favourable results (Verbiest and Paz y Geuse, 1966; Guidetti and Fortuna, 1969; Phillips, 1973) of anterior cervical surgery in myelopathy, after variable periods of follow up, and some adverse reports (Galera and Tovi, 1968) have been published. One such study (Gregorius et al., 1976) suggested that patients with myelopathy most frequently worsened as follow up lengthened and identified one group in which there was initial improvement, then a plateau, followed by worsening six to eight years after surgery.

The results of this study are favourable with 36 patients $(78 \%)$ showing improvement and 29 patients $(63 \%$ ) being able to walk unaided a decade after surgery. Questionnaire follow up has been criticised but the use of a straightforward functional scoring system allows for greater objectivity. Seven of the 17 patients in Grades 3 and 4 at follow up had other chronic diseases which probably contributed to their over-all disability. The mean age of the whole group at follow up was 70 years and, therefore, the normal restrictions imposed by advancing age should not be overlooked. Other studies (Verbiest and Paz y Geuse, 1966; Guidetti and Fortuna, 1969) have suggested that outcome may be influenced by duration of disease, its severity and age at surgery. We have been unable to relate any of these variables to outcome.

We conclude that anterior cervical decompression and fusion is useful in the treatment of spondylotic myelopathy but would not suggest that it be used exclusively. Current practice in this unit is to employ a full decompressive 
laminectomy where there is evidence of multiple level disease, a congenitally narrow spinal canal or ligamentum flavum buckling. Anterior surgery is reserved for those patients with evidence of disease localised to one or two levels.

\section{Acknowledgement}

G. B. Irvine was supported by a grant from the Northcott Devon Medical Foundation

\section{References}

BRAIN WR, NORTHFIELD DWC, WILKINSON M 1952 The neurological manif estations of cervical spondylosis. Brain 75:187-225.

Brain WR, Wilkinson M 1967 Cervical Spondylosis, WB SaUnders, Philadelphia.

Campbell AMG, Phillips DG 1960 Cervical lesions with neurological disorder. Differential diagnosis, treatment and prognosis. British Medical Journal 2:481 -485 .

ClOWARD RB 1958 The anterior approach for removal of ruptured cervical discs. Journal of Neurosurgery 15:602-617.

ClOWARD RB 1962 New Method of diagnosis and treatment of cervical disc disease. Clinical Neurosurgery 8:93-127.

CRANDAll PH, BATZDORF U 1966 Cervical spondylotic myelopathy. Journal of Neurosugery 25:57-66.

Crandall PH, Gregorius FK 1977 Long-term follow-up of surgical treatment of cervical spondylotic myelopathy. Spine 2:139-146.

DoHN DF 1966 Anterior interbody fusion for treatment of cervical disc conditions. Journal of the American Medical Association 197:897-900.

GaleRA R, Tovi D 1968 Anterior disc excision with interbody fusion in cervical spondylotic myelopathy and rhizopathy. Journal of Neurosurgery 28:305-310.

Gregorius FK, Estrin T, CRANDALl PH 1976 Cervical spondylotic radiculopathy and myelopathy. A long-term follow-up study. Archives of Neurology 33:618-625.

GUIDETTI B, ForTUNA A 1969 Long-term results of surgical treatment of myelopathy due to cervical spondylosis. Journal of Neurosurgery 30:714-721.

HARRIS P 1963 The anterior approach to excision of cervical discs. Proceedings of the Royal Society of Medicine 56:807-808.

LeEs F, TURNER JWA 1963 Natural history and prognosis of cervical spondylosis. British Medical Journal 2:1607-1610.

LUNSFORD DL, BISSONETTE DJ, ZORUB DS 1980 Anterior surgery for cervical disc disease. Part 2: Treatment of cervical spondylotic myelopathy in 32 cases. Journal of Neurosurgery 53:12-19.

NORTHFIELD DWC 1955 Diagnosis and treatment of myelopathy due to cervical spondylosis. British Medical Journal 2:1474-1477.

PhILlIPS DG 1973 Surgical treatment of myelopathy with cervical spondylosis. Journal of Neurology, Neurosurgery and Psychiatry 36:879-884.

SYMON L, LAVENDER P 1967 The surgical treatment of cervical spondylotic myelopathy. Neurology 17:117-127.

Verbiest H, PAZ Y Geuse HD 1966 Anterolateral surgery for cervical spondylosis in cases of myelopathy or nerve-root compression. Journal of Neurosurgery 25:611-622. 